\title{
User Recognition in AAL Environments
}

\author{
Ricardo Costa, Paulo Novais, Ângelo Costa, Luís Lima and José Neves
}

\begin{abstract}
Healthcare projects that intend to decrease the economical and social costs of the real ageing population phenomenon, through the de-localisation of healthcare services delivery and management to the home, have been arising in the scientific community. The VirtualECare project is one of those, so called, Ambient Assisted Living environments, which we have taken a step forward with the introduction of proactive techniques for better adapting to its users, namely elderly or chronic patients, once it is able to learn with their interaction based in contexts. This learning, however, causes the system need to know with whom it is interacting. Basic detection techniques based in possible devices that users carries along with them (e.g. RFID tags, mobile phones, ...) are not good enough, since they can lose/forgot/switch them. To obtain the expected results the technology used has to be more advanced and available in several platforms. One possible and already fairly developed technique is Facial Recognition, and it appears to be the most appropriate one to handle the problem. This document exposes the initial approach of the VirtualECare project to the Facial Recognition area.
\end{abstract}

Key words: Ambient Assisted Living, e-Health, Face Recognition

\section{Introduction}

The population ageing phenomenon [1] and specially its consequences in the healthcare and social security systems around the world, in particular in developed coun-

Paulo Novais, Ângelo Costa, José Neves

CCTC, Departamento de Informática, Universidade do Minho, Braga - Portugal e-mail: pjon@di.uminho.pt, acosta@di.uminho.pt, jneves@di.uminho.pt

Ricardo Costa, Luís Lima

CIICESI, College of Technology and Management of Polytechnic of Porto, Felgueiras - Portugal e-mail: rcosta@estgf.ipp.pt, 1lima@estgf.ipp.pt 
tries, associated with the need in providing elderly with a quality and dignified active ageing solution [2] constitutes a real and urgent problem in today's society. The rapidly ageing societies claim for better ways to treat the elderly persons with more dignity and consideration. As the ageing tendency keeps climbing, the mild-age persons are already preparing their future towards a most peaceful and supported way. This urgency raised the need for a rapid response from the several healthcare sectors, direct or indirect, players that, in most cases, have turned to the IT sector searching for answers. In this scenario the VirtualECare project [3] appeared as one possible solution, in search of an active ageing that can cope with the demands of the future of the soon-to-come elderly persons.

\subsection{Active Ageing}

According to the World Health Organisation (WHO) [2] today's society must introduce new strategies for the population ageing, as elderly population is an asset that the society is starting to properly considering, in particularly the senior professionals witch possess a number of skills and accumulated experience that need to be transferred to younger ones and/or participate in social activities [4]. In developed countries the core of the community that has 60 years old and upwards is constituted already by well educated people that has many contact with new technologies and is used to use modern devices and services, things that are already a necessity in their everyday life. Additionally, recent studies [1] show that by keeping the human been active and engaged with activities of low and high complexity is beneficial not only to the body as also, and perhaps more importantly, to the mind, so keeping an active life helps the person in several levels and fields of health.

\subsection{VirtualECare}

The VirtualECare project (Figure 1) envisions a new and effective way of providing healthcare, where the treatment will no more be institution centred but, instead, will shift to be user centred, resulting in a better and cheaper service for both the user and the provider. Although at first glance this may seem a contradiction, the lower of costs is possible through the use of new, low-cost, devices and technologies that allow the monitoring and assessment of patient vital data and location in real time. This same data, after adequate processing, can conduct to alarms, recommendations or even actions to assist the needed patient while he maintains is normal, day-today, life. These new healthcare provision approximations bring great advantages that may also be extended to relatives and friends of the patient, since they can be informed, in real time, of his actual condition allowing them to also intervene in case of necessity $[3,5]$. 


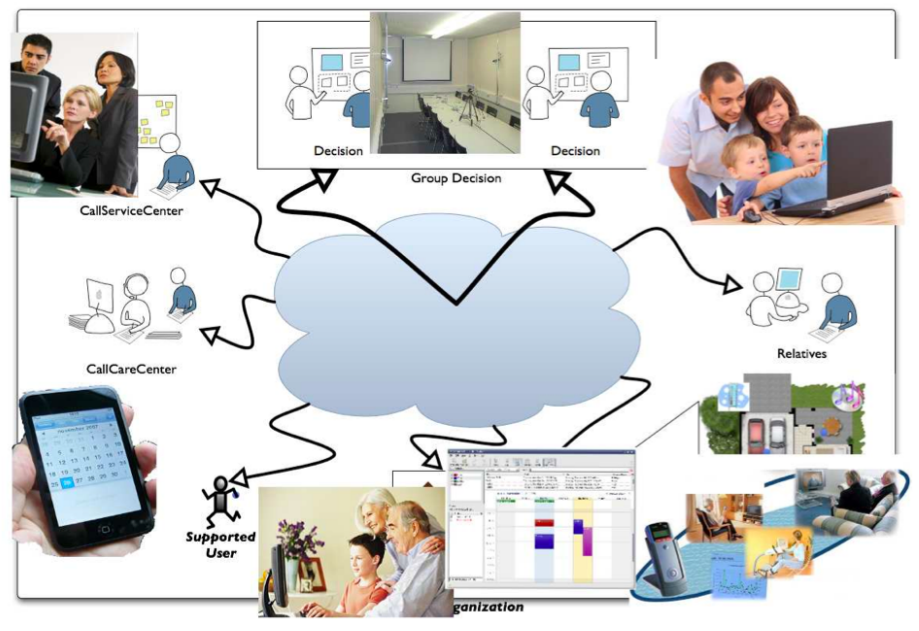

Fig. 1 The VirtualECare Project

As a consequence of this new way of healthcare provision we had the need to enrich the patient home with Ambient Intelligence (AmI) and, more concretely, Ambient Assisted Living (AAL) technologies. This approximation allowed us to better respond to the patient specific needs, modulating his home environment as needed in order to better respond to his expectations [6]. In an early stage of the system development, and because of the initial focus of the conception and targeted community, only was projected the use and activation of a singular person for each house or implementation. However, as the project evolved and new facts and community feedback where received, it was realised that there was a missing part ready to be constructed, now that we have reached a more mature implementation. We started to realise the importance of implement techniques that will allow our system not only to be capable of automatically, and without any user/patient intervention, recognise the presence of different individuals [7] but also to uniquely identify them. This individual recognition will contribute to the set of different environments that can match to different users and seamlessly work and contribute to the expected results, being the environment with the presence of several individuals the principal objective.

The VirtualECare project has already an RFID module in development, but its focus tends to another area, where the application is more oriented to an officelike environment, thus the persons and devices that are applied are very different to the persons we approach in the case that is documented here. In this case, it is not needed any control over moving objects or very frequent log-ins and log-outs. There are several cases that misfit the use of the RFID in this scenario, the most important is the security. The RFID tag can be lost or misused by another person than the user, whilst the persons face cannot be lost or even traded. 


\section{Recognition}

With the increase of the Information and Communication Technologies in all aspects and sectors of our life, a world of unprecedented scenarios is arising. Some of these scenarios are the explosions of new and different techniques of automatic and seamless individual's recognition. These techniques, used in several areas of our society (e.g. airports, industry, law enforcement), can also be applied in AmI and consequently AAL environments, not only to regulate controlled access to them, but also, as a consequence of the possibility to uniquely identify an individual, to make the necessary automatic adaptations to it, according to that specific individual needs (according to his pre configured profile). Nowadays there are several developments already in the domestic area. The personal computers, such as laptops already bring fingerprint sensors and Facial Recognition, although they are fairly primitive in terms of the functioning and detection, mainly because the companies do not use the best hardware available. Facial Detection is now the top area of the Biometric sector. It is practical since no physical interaction has to be made and if the cameras comply with high speed shuttering several faces can be processed in just a few seconds.

\subsection{Biometric}

Biometric recognition uses our distinctive physiological (e.g., fingerprints, face, retina, iris) and behavioural (e.g., gait, signature) characteristics for automatic recognising. These biometric distinctive physiological and behavioural characteristics cannot be easily misplaced, forged and/or shared [8]. They are, inclusively, considered more reliable for person recognition than any other traditional token or knowledge-based methods making biometrics very suited for AmI/AAL environments, and this is especially true for a biometric physiological characteristic such as face which is one of the most common methods of recognition that humans use in their visual interactions, and allows to recognise the user in a not intrusive way without any physical contact with the sensor [9]. Using several points of recognition the system can construct a valid profile of the possible user, being registered in the main system the information can spread to the remaining system without the interaction of the user, being available at once the capacity of logging into the system.

\subsection{Facial Recognition}

Facial recognition, as above already mentioned, is one of the possible biometric physiological characteristics that can be used to uniquely identify a person. Normally, these kind of systems are on 3D features to verify the identity of subjects accessing the controlled AmI environment and to customise the available services 


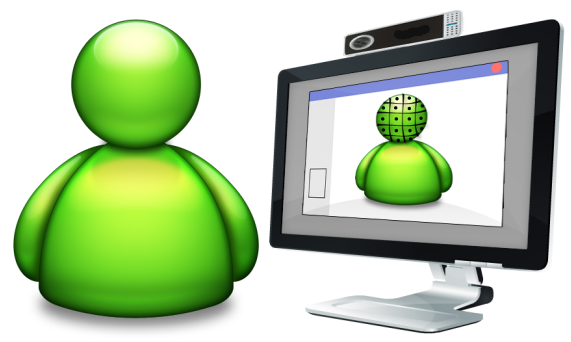

Fig. 2 Facial Recognition

accordingly. In other terms, it allow us to add a social dimension to man-machine communication and thus may help to make such environments more attractive to the human user [9].

The facial signature can be captured nowadays by a simple web-cam or camera as they process enough image quality and speed do do it so. The facial pinpoints consist in the marks and features of the user face, usually nodal points. In terms of the 3D facial recognition, the technology this project intent to embrace, several captures of the face are taken in different angles and facial expressions, mapping a more realistic approach to the user face. This is done so that the user can be more rapidly and accurately detected, being in the most advanced cases possible to recognise the head silhouette and in fairly low light conditions, with the help of infra-red cameras. With the independence of colours and natural light conditions it is safe to say that this type of recognition can work in any normal in-house conditions, not to mention the security in recognition, provided by the accuracy that this system has. After the initial capture and processing any modern camera is able to do the system login, being only advised the use of infra-red lights to stabilise the surrounding light conditions and create a mini environment in terms of light exposure.

The enrolment of the several captures or the 3D scan make a perfect model that has millions of localisation points, these points are taken as markers and if the face is presented to the scanner in a awkward position, because there are several referential points the annalist agent can mismatch the received image to a single point and construct the rest of the face by pattern matching, applied by the surface texture analysis model.

\section{VirtualECare Recognition Module}

The VirtualECare system architecture (Figure 3) was idealised to be a modular one, in order to allow the addition of new modules in the future, in the measure of necessity and system evolving. Heavily based in the OSGi technology and decentralised systems this project has the capacity of receiving new modules, either locally or in the central system (cloud). Implemented under the Multi-Agent paradigm all the 
Costa R., Novais P., Costa A., Lima L., Neves J., User Recognition in AAL Environments, in Ambient Intelligence, Future Trends International Symposium on Ambient Intelligence (ISAmI 2010), Augusto JC., Corchado JM, Novais P., Analide C. (Eds.), Springer Series Advances in Intelligent and Soft Computing, vol. 72, ISBN 978-3-642-13267-4, pp 177-184, (International Symposium on Ambient Intelligence, Guimarães, Portugal, 16-18th June/2010), 2010.

modules and agents in the system communicate with each other creating and intricate system of communication and information sharing. Each module can have several agents and control them independently but it keeps connection with the remaining modules in a meta-communication form. Several modules are already working in both system types, being a sensors monitoring system and a user intelligent calendar organiser two of the most relevant modules and actually well beyond the proof-of-concept phase. The project has already the ability to identify a user based in some kind of device he was carrying, like a RFID tag or a mobile phone, however this was not a ideal situation as users tend to forget to carry them around the house and/or makes very difficult the task of knowing their exact location, typically the target users of this project.

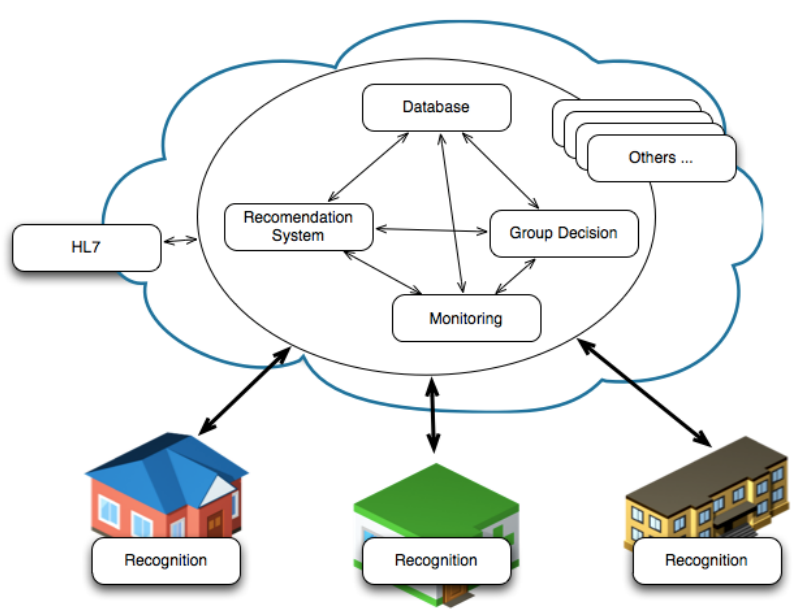

Fig. 3 VirtualECare Modular Architecture with the Recognition Module

\subsection{Implementation}

Due to the modular characteristic, theoretically, it should be trivial to add any kind of recognition module that meets the project technology standards. However, during the definition and architecture phase of the recognition module, we realised it should not stand in the "cloud" like all the others, once the recognition should take place in each different environment, despite the user identification being needed in the entire system.

Due to this fact, we opted to deploy the recognition modules inside each user environment (Figure 4), interconnected with the existing local technologies (e.g. OSGi and Agents). This decision also allowed us to be able to keep the base characteristics of the environment working (including recognition) even if, for some reason, 
Costa R., Novais P., Costa A., Lima L., Neves J., User Recognition in AAL Environments, in Ambient Intelligence, Future Trends International Symposium on Ambient Intelligence (ISAmI 2010), Augusto JC., Corchado JM, Novais P., Analide C. (Eds.), Springer Series Advances in Intelligent and Soft Computing, vol. 72, ISBN 978-3-642-13267-4, pp 177-184, (International Symposium on Ambient Intelligence, Guimarães, Portugal, 16-18th June/2010), 2010.

the connection to the "cloud" was lost. In terms of the technology point of view there can be a camera in each room or terminal or only one to the entire system, this can be adapted to each environment/user necessity. As there will be agents locally controlling the capture of the information the preservation of the information will be secured and then relayed to the "cloud" to be conveniently logged and processed. Each user has to be inserted in the system by a technician and all the persons that sporadically come in touch with terminal can request to the support line an authorisation or use a predefined "guest" log-in.
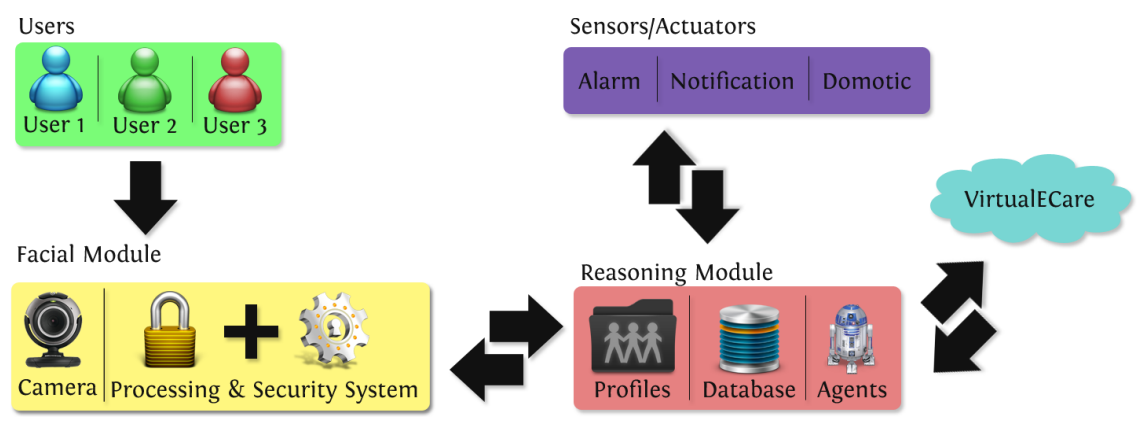

Fig. 4 Designed Architecture

The availability of this system can be used to control the operation of the several devices present in the house, activated personalised profiles and change the devices configuration in each room the user enters, open automatically the front door without the need of a key, keep track of where the user enters and exits between other several hypotheses available.

\subsection{Security}

In terms of the added security value, it is of the most interesting factor. As it was previously mentioned the face is one thins that is hard to forge or manipulate so this system is of the uttermost security level. In the verification phase it is assured that already the user to be logged is in fact the user registered in the system. The use of the cameras can also be used in several other purposes, like monitoring every person that approaches the front door of the house and register them in the database for further analysis and processing, being one of the abilities the easy introduction of that person in the system, if the user find it useful. Furthermore the use of the cameras can also be used in an extreme case to monitor and report to the right service/person of possible cases of urgency or emergency happening the the user home. Any stranger reported to the system can be automatically notified to the user or relatives for authorisation or it refuse. 
Costa R., Novais P., Costa A., Lima L., Neves J., User Recognition in AAL Environments, in Ambient Intelligence, Future Trends International Symposium on Ambient Intelligence (ISAmI 2010), Augusto JC., Corchado JM, Novais P., Analide C. (Eds.), Springer Series Advances in Intelligent and Soft Computing, vol. 72, ISBN 978-3-642-13267-4, pp 177-184, (International Symposium on Ambient Intelligence, Guimarães, Portugal, 16-18th June/2010), 2010.

\section{Conclusions and Future Work}

In this paper we present the idea of bringing the, already available, new technologies and techniques used for biometric identification, specially the ones based on facial recognition. We believe the introduction of such techniques in AmI/AAL environment will open new horizons and allow such environments, not only to be better accepted by its users, but also to more adequate respond to their needs and expectations. The introduction of the Recognition Module, based in the above presented Facial Recognition Techniques, in the VirtualECare system brought several new facilities and user friendless, thus contributing to one of the objectives of AmI environments. We are now able to uniquely identify each user of the system without his interaction, and even if for now, that may not seem very impressive, the addition of this simple capacity opened our horizons, since we can start a new line of research for multi-user support inside a single environment and, for instance, adequate different rooms environment to the user inside it. Obviously, the future introduction of this new recognition module will increase the solution cost, but we hope to demonstrate the gains associated with maximal user dematerialisation of mobile devices and with the system additional personification.

We are now working on developing of this new presented module and verifying how it can be seamless introduced in our AAL system. We are also searching for low cost devices, which will allow us not to absurdly increase the solution costs, and searching for some R\&D partners and developers in this, for us, new area of Facial Recognition.

\section{References}

1. P. D. DESA, World Population Ageing: 1950-2050. United Nations, 2001.

2. W. H. Organization, Active Ageing: Towards Age-Friendly Primary Health Care. World Health Organization, 2004.

3. R. Costa, P. Novais, L. Lima, D. Carneiro, D. Samico, J. Oliveira, J. Machado, and J. Neves, "Virtualecare: Intelligent assisted living," in Electronic Healthcare, pp. 138-144, 2009.

4. L. Camarinha-Matos and H. Afsarmanesh, The Need for a Strategic R\& D Roadmap for Active Ageing. 2009.

5. R. Costa, P. Novais, L. Lima, J. B. Cruz, and J. Neves, "Virtualecare: Group support in collaborative networks organizations for digital homecare," in Handbook of Digital Homecare, pp. 151-178, 2009.

6. D. Carneiro, R. Costa, P. Novais, J. Neves, J. Machado, and J. Neves, "Simulating and monitoring ambient assisted living," in Proceedings of the ESM 2008 - The 22nd annual European Simulation and Modelling Conference, Proceedings of the ESM 2008, 2008.

7. K. Ducatel, M. Bogdanowicz, F. Scapolo, J. Leijten, and J. Burgelman, Scenarios for ambient intelligence in 2010. Office for Official Publications of the European Communities, 2001.

8. D. Maltoni, D. Maio, A. Jain, and S. Prabhakar, Handbook of Fingerprint Recognition. Springer, New York, US, 2003.

9. A. Abate, S. Ricciardi, and G. Sabatino, "3d face recognition in a ambient intelligence environment scenario," Face Recognition, 2007. 